Revista Tecné, Episteme y Didaxis: TED. Año 2014, Número Extraordinario. ISSN Impreso: 0121-3814, ISSN web: 2323-0126

Memorias, Sexto Congreso Internacional sobre Formación de Profesores de Ciencias. 08 al 10 de octubre de 2014, Bogotá

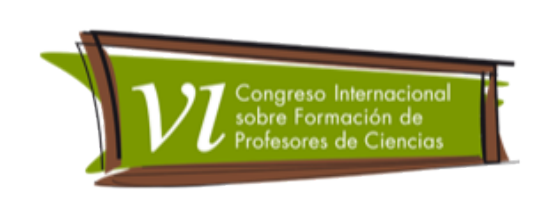

\title{
Interdisciplinaridade E Realidade Social: Tijolo Como Tema Gerador Na Educação Básica - Nível Médio
}

Silva, Márcio A², Souza, Gilmar P22, Gomes, Suzana S33

Categoria 2. Trabalho de investigação concluído

\section{Resumo}

Apresentamos um recorte de nossa pesquisa de mestrado sobre interdisciplinaridade e contextualização. O tema gerador é tijolo e foi desenvolvido em uma cidade onde o artefato é a principal atividade econômica. Os professores e alunos da segunda série do ensino médio noturno de uma escola pública são os protagonistas. No âmbito de pesquisa-participante, considerando os estudos de Ivani Fazenda sobre interdisciplinaridade e Paulo Freire em educação libertária, apresentou-se a proposta a comunidade. Relatamos a postura e as atividades desenvolvidas pelos professores, com enfoque nas aulas de química e de português. Os alunos trabalhadores conduziram boa parte das temáticas ensinando e aprendendo. O trabalho teve mérito, mas nos preocupa uma discussão detalhada sobre a interdisciplinaridade, a estrutura escolar e o processo avaliativo.

\section{Palavras- chave}

Interdisciplinaridade, contexto social, tijolo.

\section{Introdução}

Descrevemos uma parte de nossa pesquisa no Mestrado em Ensino de Ciências (MPEC) da Universidade Federal de Ouro Preto. Após os estudos teóricos sobre a interdisciplinaridade dos mais recentes documentos oficiais e da concepção de pesquisa participante, propusemos a um grupo de professores de uma região produtora de tijolos, uma parceria para a construção e a avaliação de um processo interdisciplinar de ensino baseado na principal fonte econômica da região.

O objetivo deste trabalho foi avaliar as condições para que uma prática interdisciplinar possa ser implantada em uma escola com longa vivência em ensino tradicional.

\footnotetext{
1 Universidade Federal de Ouro Preto - UFOP - marciogomers@gmail.com

2 Universidade Federal de Ouro Preto - UFOP - alquimistagil@gmail.com

3 Universidade Federal de Minas Gerais - UFMG - suzanasgomes@fae.ufmg.br
} 
Revista Tecné, Episteme y Didaxis: TED. Año 2014, Número Extraordinario. ISSN Impreso: 0121-3814, ISSN web: 2323-0126

Memorias, Sexto Congreso Internacional sobre Formación de Profesores de Ciencias. 08 al 10 de octubre de 2014, Bogotá

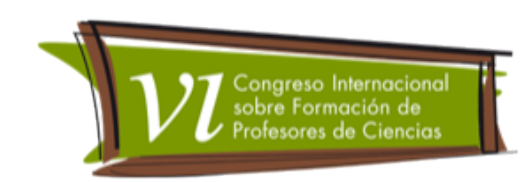

Os eixos norteadores são os estudos de Ivani Fazenda sobre interdisciplinaridade, de educação libertária de Paulo freire, dos Parâmetros Curriculares Nacionais (PCNs) e do Currículo Básico Comum (CBC) da Secretaria de Educação de Minas Gerais.

Os participantes desta pesquisa são professores da segunda série do ensino médio noturno de uma escola pública estadual e seus alunos. Por se tratar de pesquisa participante o pesquisador esteve presente em todos os momentos de planejamento, execução e avaliação das atividades.

\section{Referencial teórico}

Os estudos de Ivani Fazenda (2012), apontam que o movimento da interdisciplinaridade surgiu na Europa, em meados da década de 1960, época em se insurgem os movimentos estudantis, reivindicando um novo estatuto de universidade $e$ de escola.

Nos dias atuais, a palavra de ordem nos documentos oficiais (PCNs e CBC) tem sido "interdisciplinaridade". Assim se faz modismo, sem se refletir na essência do termo. Ivani assim destaca:

Muitos já falam na mudança, chegam até a vislumbrar a possibilidade dela, porém, conservam na sua forma própria de ser educador, de ser pesquisador, de dar aulas um patriarcado que enquadra, que rotula, que modula, que cerceia, que limita. Poucos são os que se aventuram a viver alteridade, porque é caro o preço que se paga pela mudança de ciclo. (Fazenda - 2012, pág.42)

No texto referencial do CBC/química, da Secretaria de Estado da Educação de Minas Gerais (2007) podemos perceber a interdisciplinaridade da seguinte forma:

Integração dos Saberes Disciplinares - Esse critério é importante na superação da fragmentação com que vêm sendo tratados os conteúdos. Nessa perspectiva é importante estabelecer diálogos e conexões entre as abordagens de conteúdos químicos, físicos e biológicos, sem nos esquecermos das dimensões históricas, dos aspectos éticos e dos interesses diversos que estão por trás do conhecimento científico. (CBC/química/SEEMG. pág.26 - 2007)

Desta forma, o diálogo deverá ir além da química, com dimensões históricas, aspectos éticos e interesses diversos. Reforça-se o diálogo. Paulo Freire (2011) cita: 
Revista Tecné, Episteme y Didaxis: TED. Año 2014, Número Extraordinario. ISSN Impreso: 0121-3814, ISSN web: 2323-0126

Memorias, Sexto Congreso Internacional sobre Formación de Profesores de Ciencias. 08 al 10 de octubre de 2014, Bogotá

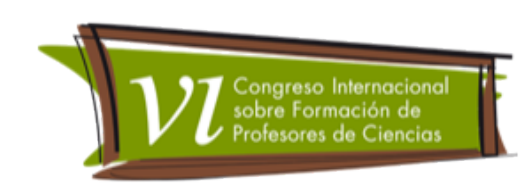

Enquanto na prática "bancaria" da educação, antidialógica por essência, por isto, não comunicativa, o educador deposita no educando o conteúdo programático da educação, que ele mesmo elabora ou elaboram para ele, na prática problematizadora, dialógica por excelência, este conteúdo, que jamais é "depositado", se organiza e se constitui na visão do mundo dos educandos, em que se encontram seus temas geradores. (...). A tarefa do educador dialógico é, trabalhando em equipe interdisciplinar este universo temático recolhido na investigação, devolvê-lo como problema, não como dissertação, aos homens de quem recebeu. (Paulo Freire, pág. 142, 2011)

\section{Metodologia}

Pesquisamos com os alunos se eles gostariam de analisar, de forma interdisciplinar, a cadeia produtiva dos tijolos através de um questionário. Mostramos aos professores o resultado indicando a boa receptividade do tema. Os professores se posicionaram a favor do projeto e sugeriram uma visita a uma olaria.

$\mathrm{Na}$ visita conhecemos todas as etapas, desde o depósito da argila até o carregamento dos tijolos nos caminhões. Elaboramos estratégias para que um ensino contextualizado e interdisciplinar ocorresse. Fizemos também uma análise sobre o que os professores entendiam por interdisciplinaridade.

Criamos uma ferramenta de comunicação (blog), onde foi feito o registro do trabalho passo a passo. E por fim, sintetizamos as contribuições de cada disciplina, conforme o quadro 01.

Quadro 01. Disciplinas e contribuições individuais

\begin{tabular}{|l|l|}
\hline \multicolumn{1}{|c|}{ DISCIPLINA } & \multicolumn{1}{c|}{ ABORDAGEM } \\
\hline Biologia - BIO & Estudo do pó de balão/ propostas de sustentabilidade. \\
\hline Educação Física - EF & Postura nos trabalhos com cerâmica \\
\hline Filosofia - FIL & A ética no mundo cerâmico. \\
\hline Física - FIS & Termodinâmica - O estudo dos fornos. \\
\hline Geografia - GEO & Dados sociais e econômicos \\
\hline História - HIS & Evolução da cerâmica na região. \\
\hline
\end{tabular}


Revista Tecné, Episteme y Didaxis: TED. Año 2014, Número Extraordinario. ISSN Impreso: 0121-3814, ISSN web: 2323-0126 Memorias, Sexto Congreso Internacional sobre Formación de Profesores de Ciencias. 08 al 10 de octubre de 2014, Bogotá

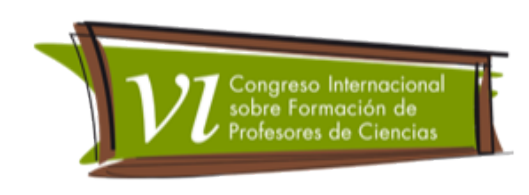

\begin{tabular}{|l|l|}
\hline \hline Inglês - ING & Palavras inglesas no mundo cerâmico. \\
\hline Matemática - MAT & Medidas e unidades/ Gráficos e Porcentagem \\
\hline Português - PORT & Construção de textos, redação \\
\hline Química- QUI & Estudo do pó de balão/ Tipo de tijolos/ Métodos de produção. \\
\hline Sociologia - SOC & Renda e Consumo. \\
\hline
\end{tabular}

Fonte: Quadro elaborado após discussões entre os professores.

Os fatos foram registrados em diário de campo, fotografados e materiais foram arquivados para a construção das análises desse trabalho implicando nos objetivos a que nos dispusemos.

\section{Resultados}

O contato com os estudantes mostrou que muitos gostariam de estudar sobre os tijolos envolvendo as disciplinas da escola. O percentual foi de $85 \%$ em uma turma de 40 alunos.

Analisamos os conceitos prévios que os professores, licenciados, tinham sobre interdisciplinaridade. Os questionários mostraram que a interdisciplinaridade é vista como:

A junção de disciplinas, ajudando uma a outra. (SOC.)

É o diálogo entre diferentes disciplinas, como começamos a trabalhar no sábado. A interdisciplinaridade ocorre por meio de integração, diálogos e contrapontos entre as disciplinas. ( PORT.)

É a junção de disciplinas diferentes visando melhorias. (QUI.)

Após discussão sobre o assunto com os professores foi elaborado o quadro a seguir:

Quadro 02. Comparação entre educação tradicional e educação interdisciplinar

\begin{tabular}{|c|c|}
\hline Educação Tradicional & Educação Interdisciplinar \\
\hline Professor transmissor & Professor pesquisador \\
\hline Aluno passivo & Aluno ativo \\
\hline
\end{tabular}


Revista Tecné, Episteme y Didaxis: TED. Año 2014, Número Extraordinario. ISSN Impreso: 0121-3814, ISSN web: 2323-0126

Memorias, Sexto Congreso Internacional sobre Formación de Profesores de Ciencias. 08 al 10 de octubre de 2014, Bogotá

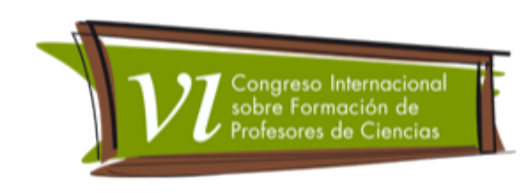

\begin{tabular}{|c|c|}
\hline \hline Professor opressor & Professor incentivador \\
\hline Aluno repetidor & Aluno pesquisador \\
\hline Relação vertical & Relação horizontal \\
\hline Professor autoritário & Professor autoridade \\
\hline Disciplinas isoladas & Disciplinas entrelaçadas \\
\hline Descontextualização & Contextualização \\
\hline Ignora a realidade & Realidade - tema gerador \\
\hline Avaliação sistêmica & Avaliação permanente \\
\hline
\end{tabular}

Fonte: Quadro elaborado após estudos sobre interdisciplinaridade de Fazenda e de Paulo Freire.

Tendo em vista o quadro, destacaremos os trabalhos desenvolvidos pelos professores de química e de português.

Inicialmente o professor de PORT solicitou que os alunos se dividissem em grupos e que em cada grupo houvesse pelo menos um aluno-trabalhador de olaria. Os trabalhadores explicitaram sobre o funcionamento de uma cerâmica e que uma redação fosse feita. Nos chamou atenção as dificuldades para sintetizar as ideias em frases curtas e o uso do singular/plural. Diante disso o professor de PORT dinamizou suas aulas para esses itens.

Na aula de química os alunos levaram para a sala dois tipos de tijolos: o de primeira e o de segunda classes. O tijolo de primeira classe não apresenta trincos, têm coloração homogênea avermelhada e tem alta dureza. O de segunda classe possui trincados, colorações entre vermelho claro e escuro e são menos duros. Para distingui-los o professor de QUI sugeriu então que fizessem a medida do ponto de ebulição da água. Essa discussão se deve porque o tijolo para ir à "queima" deve conter no máximo 8\%, em massa, de água. Quando há excesso de água na massa do tijolo ocorre consequentemente uma maior quantidade de vapor, o que danifica a estrutura do tijolo tornando-o de segunda classe. Notamos que os alunos trabalhadores desconheciam tal justificativa para que a secagem fosse um papel decisivo na qualidade. Houve um debate bastante satisfatório.

O professor QUI trouxe para a sala os materiais: argila, areia, terra, pó de balão e água. O material que despertou maior curiosidade foi o pó de balão. Inicialmente os 
Revista Tecné, Episteme y Didaxis: TED. Año 2014, Número Extraordinario. ISSN Impreso: 0121-3814, ISSN web: 2323-0126 Memorias, Sexto Congreso Internacional sobre Formación de Profesores de Ciencias. 08 al 10 de octubre de 2014, Bogotá

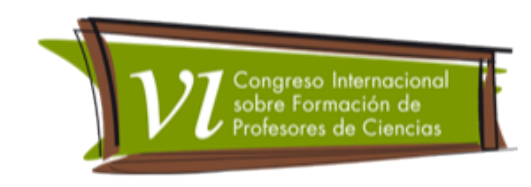

alunos-trabalhadores explicaram a sua utilização e cuidados. O pó de balão faz que com o que o tijolo sofra a "queima" em torno de $950^{\circ} \mathrm{C}$. Quando não se utiliza o pó de balão a temperatura media do forno é em torno de $120{ }^{\circ} \mathrm{C}$, consumindo mais lenha. Os alunos citaram que os oleiros compram o material das siderúrgicas e que deve ser guardado em local apropriado pois há rumores que seja cancerígeno. Dispondo de interesse sobre o assunto, o professor QUI solicitou aos alunos que pesquisassem sobre o material no laboratório de informática da escola.

Diante da situação questionada pelos alunos sobre danos à saúde os professores de QUI e de BIO incentivaram a uma nova pesquisa. Encontraram relatos de danos mas também relatos do pó de balão ser usado como adubo. O professor de BIO organizou um experimento com o plantio de alface para verificar a atuação como adubo. 0 pesquisador, na condição de participante, entrou em contato com uma siderúrgica e obteve a resposta de que o pó de balão pode ser usado como adubo e não há indícios de ser cancerígeno.

Nessa fase o professor de PORT entregou aos alunos um texto sobre tijolos e classes sociais. O trabalho destaca a cadeia produtiva e a situação social dos trabalhadores. Os alunos que não trabalham em olarias também se identificam devido a convivência com os familiares e enxergam as dificuldades e as trajetórias da classe operária. Apontam os que levam lucro no processo e os que são explorados.

Duas maquetes foram montadas pelos estudantes e apresentadas a comunidade.

\section{Conclusões}

Registramos aqui os pontos que mais contribuíram para a construção da interdisciplinaridade em uma escola que tem vivencia de ensino tradicional há muito tempo e os obstáculos que uma proposta dessa natureza enfrenta.

Verificamos que os passos para uma educação interdisciplinar começaram a se desenvolver. Os professores foram incentivadores, os alunos foram ativos no processo, a contextualização ocorreu, o tema gerador tem estreita relação com os protagonistas. Os fatos que mais nos incomoda é a estrutura escolar e o processo avaliativo.

Os professores, dentro da logística de trabalho escolar, vivem isolados.. Três segmentos são bem observados na escola: Direção, e aqui inclui a supervisão, Secretaria e os Professores. Esses três segmentos dialogam entre si na escola, mas ou se trata de indisciplina dos alunos ou de notas, diários e de provas a serem entregues. A burocracia é tão grande que a secretaria escolar e a direção não são vistas como assessoras do processo de ensino, mas como lugares de cobrança. É necessário que se 
Revista Tecné, Episteme y Didaxis: TED. Año 2014, Número Extraordinario. ISSN Impreso: 0121-3814, ISSN web: 2323-0126 Memorias, Sexto Congreso Internacional sobre Formación de Profesores de Ciencias. 08 al 10 de octubre de 2014, Bogotá

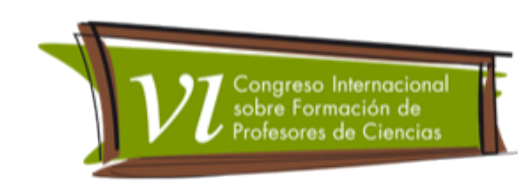

reestruture a escola pública estadual. É necessário a existência de um setor de apoio pedagógico extremamente dinâmico que participe ativamente com os professores, colaborando sem medir esforços, para que o aluno seja o foco do processo. Notou-se claramente que o aluno não é o foco do processo dentro da atual logística escolar. 0 pesquisador-participante assumiu tarefas que sem as quais o projeto teria dificuldades de caminhar. Podemos citar, por exemplo, a parte tecnológica, a confecção de materiais e até correção de atividades desenvolvidas pelos alunos.

O fator avaliativo também merece uma discussão aprofundada dentro do ambiente escolar. Os professores tem, por suas vivencias escolares e de formação universitária, uma cultura de "pontos" enraizada em suas trajetórias. E essa trajetória se faz novamente presente em suas práticas docentes. Alunos e professores se tornam reféns de "pontos" que devem ser obtidos, registrados e informados à Secretaria. Além disso há sistemas de avaliação externa, do próprio Estado, com cobrança de conteúdos estanques, impedindo projetos como os dessa natureza. Essas avaliações externas direcionam para o medo e para a insegurança, já que é o fator usado pelo Estado para qualificar a escola e os professores, inclusive com retorno financeiro.

E finalmente ressaltamos aqui, a avaliação a partir da visão dos estudantes. Alguns citaram que gostam mais do outro jeito de "aprender", porque é mais fácil e exige menos. Outros alunos, a maioria, responderam que estão dispostos a um novo trabalho interdisciplinar. Os professores ressaltaram que o tempo foi pouco para a discussão porque o tema se abriu. Esse é um argumento marcante que mostra que a interdisciplinaridade abre caminhos para novas propostas, como aponta Fazenda e também Freire.

\section{Referências bibliográficas}

Fazenda, I. (org.). (2001). Interdisciplinaridade: dicionário em construção. São Paulo: Cortez,.

(org.). (2012) Interdisciplinaridade: História, Teoria e Pesquisa. 18. Ed. São Paulo: Papirus,.

(org.). (2008). O que é interdisciplinaridade? São Paulo: Editora Cortez,.

Garcia, J., (2008.) Revista Educação Pública, Cuiabá, v.17, n 35, pág. 363-378, set-dez.

Freire, P., (2011) Pedagogia do Oprimido. 50 Ed. Rio de Janeiro: Paz e Terra,. (2011) Educação como Prática da Liberdade. 14 Ed. Rio de janeiro: Paz e Terra,.

Minas, G., Currículo Básico Comum - CBC - Secretaria de Estado da Educação: 
Revista Tecné, Episteme y Didaxis: TED. Año 2014, Número Extraordinario. ISSN Impreso: 0121-3814, ISSN web: 2323-0126

Memorias, Sexto Congreso Internacional sobre Formación de Profesores de Ciencias. 08 al 10 de octubre de 2014, Bogotá

http://crv.educacao.mg.gov.br/sistema_crv/index2.aspx??id_objeto=23967 acesso em 13 de novembro de 2013.

Ribeiro, E. D. L., (2011) Estudo Comparativo Entre Sistemas De Limpeza De Gases De Alto-Forno Em Siderúrgicas Não-Integradas A Carvão Vegetal E Alternativa De Reaproveitamento Do Pó Do Balão. Tese de Doutorado: Belo Horizonte/UFMG, pág. 66 -. Disponível em:

http://www.bibliotecadigital.ufmg.br/dspace/bitstream/handle/1843/BUOS8R9QHB/eduardo_delano_I._ribeiro_1.pdf?sequence=1 acesso em 03 de março de 2014. 